\author{
Accelerator Division \\ Alternating Gradient Synchrotron Department \\ BROOKHAVEN NATIONAL LABORATORY \\ Upton, New York 11973 \\ Accelerator Division \\ Technical Note
}

AGS/AD/Tech. Note No. 457

Radiation Impact on VME Station Memory

N. Schumburg

March 4, 1997 


\section{RADIATION IMPACT ON VME STATION MEMORY Niels Schumburg}

\section{INTRODUCTION}

To determine what effect radiation would have on a forth coming SWIC instillation on the experimental floor, a radiation impact test was conducted. A VME station with a single CPU card with 4 megabytes of memory and an Ethernet connection was positioned within the fenced in area of the B1's line calorimeter. It was located by BLD 966 and is part of E917. The VME station was initially placed on a cart with a chipmunk in front of the calorimeter. There was a remote box attached to the chipmunk to measure radiation pulses over a fixed time period. Although the scalar readouts gave integer values for each 60 second time period, three readings were taken and averaged for each radiation sample.

The station, running the VxWorks OS, had 20 standard AGS tasks. Included was a memory test which took 2 copies of 500 Kbytes of random data that was continuously compared for mismatches. VxWorks was employed to observe memory "upsets" and system hang-ups. The VME station power cord was brought to the outside of the fence for a local reset capability.

\section{TEST RESULTS}

Test number 1 was run from December 29, 1996 till January 7, 1997 during a heavy ion run. The cart was placed 3 feet in front of the calorimeter. The radiation levels varied from 26.10 $\mathrm{mrem} / \mathrm{hr}$ to $37.13 \mathrm{mrem} / \mathrm{hr}$ with an 8 sample average of $31.73 \mathrm{mrem} / \mathrm{hr}$.

Test number 2 was carried out with the cart located 12 feet in front of the calorimeter and was run from January 7 till January 15 during the same heavy ion run. The radiation levels varied from 8.58 to $15.4 \mathrm{mrem} / \mathrm{hr}$ with an 8 sample average of $10.45 \mathrm{mrem} / \mathrm{hr}$.

For test number 3 the cart was moved to a radiation free area. Data was collected from January 16 till January 28 . There were no system crashes or memory upsets.

A comparison of the three runs is given in Table 1.

\section{TABLE 1}

\begin{tabular}{c|c|c|c|c|c} 
Test No. & $\begin{array}{l}\text { Average } \\
\text { Dosage }\end{array}$ & $\begin{array}{l}\text { Memory } \\
\text { Upset }\end{array}$ & $\begin{array}{c}\text { System } \\
\text { Crashes }\end{array}$ & Beam Time & $\begin{array}{c}\text { Exposure } \\
\text { Per Upset }\end{array}$ \\
1 & $31.73 \mathrm{mrem} / \mathrm{hr}$ & 17 & 1 & $178.5 \mathrm{hrs}$ & $333.16 \mathrm{mrem} / \mathrm{upset}$ \\
2 & $10.45 \mathrm{mrem} / \mathrm{hr}$ & 5 & 0 & $158.38 \mathrm{hrs}$ & $331 \mathrm{mrem} / \mathrm{upset}$ \\
3 & $0.4 \mathrm{mrem} / \mathrm{hr}$ & 0 & 0 & $288 \mathrm{hrs}$ & not determined
\end{tabular}

Fig 1 is a graphical representation of memory upsets as a function of total exposure for 1 Mbyte of memory. 


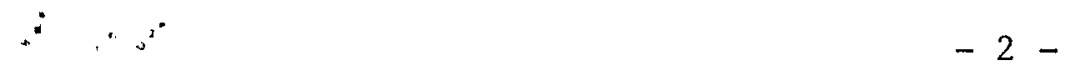

\section{CONCLUSIONS}

This test has demonstrated that memory integrity is adversely affected by radiation exposure. The relationship between memory upset and total dosage for 1 Mbyte of memory is almost linear. For a weekly upset rate of less than about 1 per Mbyte will require instillation in an area with a dose rate of approximately $2.0 \mathrm{mrem} / \mathrm{hr}$. Tests 1 and 2 also demonstrated that not all memory upsets cause system crashes and because, sensitive operational memory is a smaller segment of total memory, the VME station did recover from most but not all upsets. 
VME Station Test FIG 1

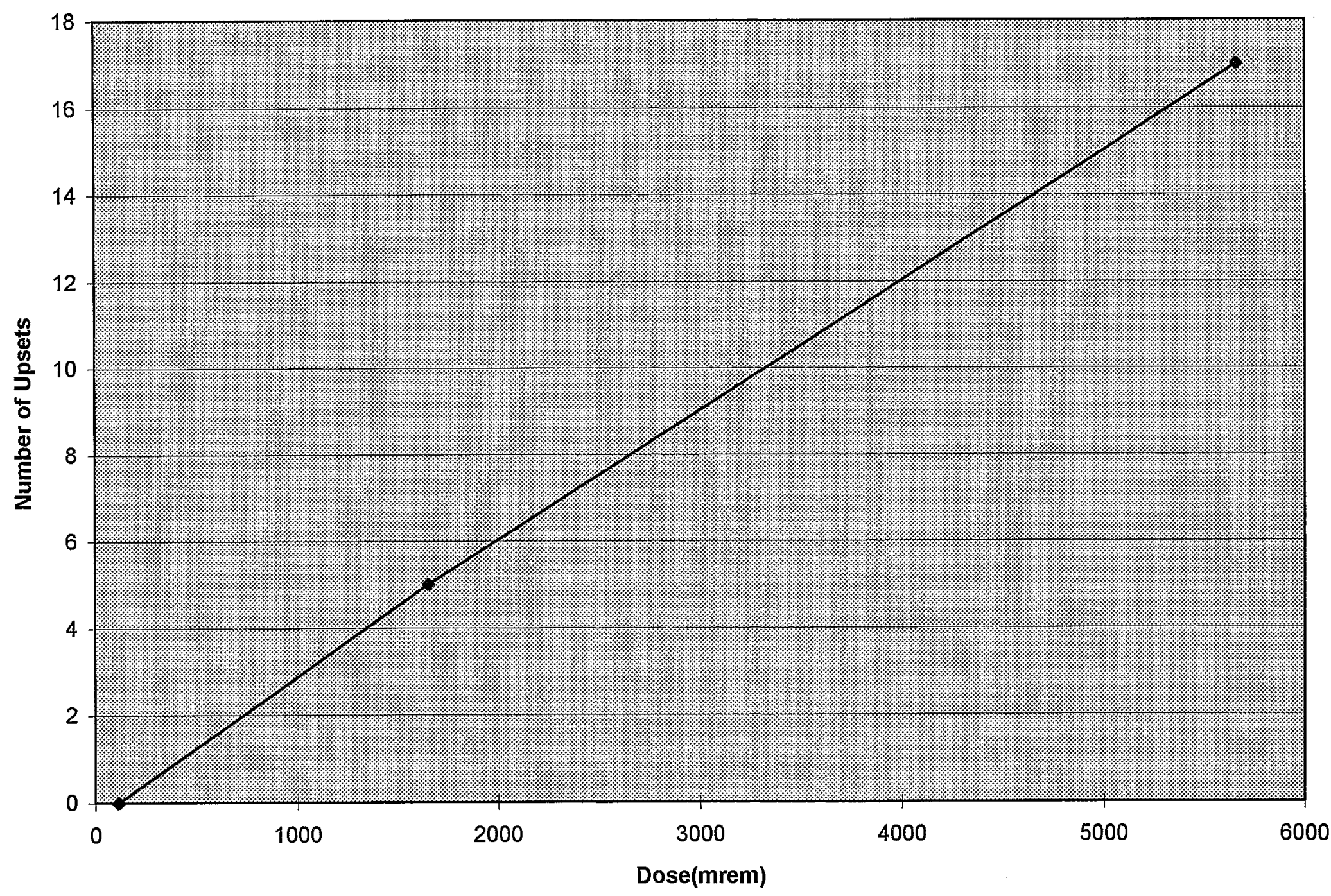

